\title{
B, N dual-doped Graphene/Au@Pt Nanomaterials as Sensor for Determination of Aflatoxin $B_{1}$
}

\author{
Shaoping Feng ${ }^{1,2}$, Jinming Meng ${ }^{1,2}$, Jinming Guo ${ }^{1,2}$, Xianlan Chen ${ }^{1,2, *}$, Guowei Zhang ${ }^{1,2, *}$, Wei Liu ${ }^{1,2, *}$, \\ Guiyang Liu ${ }^{1,2}$, Guangming Yang ${ }^{1,2}$, Hongyan Sun ${ }^{1,2}$ \\ ${ }^{1}$ College of Science, Honghe University, Mengzi, 661199, Yunnan, P.R.China \\ ${ }^{2}$ Local Characteristic Resource Utilization and New Materials Key Laboratory of Universities in \\ Yunnan, Honghe University, Mengzi, 661199, Yunnan, China \\ *E-mail: 13489086418@163.com, yunnmzh@126.com, liuwei4728@126.com
}

doi: $10.20964 / 2020.08 .97$

Received: 16 April 2020 / Accepted: 31 May 2020 / Published: 10 July 2020

In this study, B, N dual-doped graphene/Au@Pt nanomaterials (BN-G/Au@Pt NRs) was prepared by high pressure hydrothermal approach with the mass ratios of graphemes oxide $(\mathrm{GO})$, urea $\left(\mathrm{CH}_{4} \mathrm{~N}_{2} \mathrm{O}\right)$ and $\mathrm{B}_{2} \mathrm{O}_{3}$ were 1:25:30. BN-G/Au@Pt NRs have plenty of monolayer nanosheets with large-area and maintain the characteristic three dimension porous structure of grapheme. More importantly, the assynthesized BN-G/Au@Pt NRs present advantageous biocompatibility and multivalent affinity interactions with anti-AFB ${ }_{1}$, which can amplify immunoreactions. Therefore, the designed immunosensor of BN-G/Au@Pt NRs/anti-AFB $1 / \mathrm{BSA} / \mathrm{AFB}_{1} / \mathrm{GCE}$ can be used to determinate $\mathrm{AFB}_{1}$ under optimal condition and exhibit excellent sensitivity with a wide linear range from $0.025 \mathrm{ng} \cdot \mathrm{mL}^{-1}$ to $25.00 \mathrm{ng} \cdot \mathrm{mL}^{-1}$ and low the detection limits of $0.017 \mathrm{ng} \cdot \mathrm{mL}^{-1}$. Moreover, the designed BN-G/Au@ $\mathrm{Pt}$ NRs/anti-AFB ${ }_{1} / \mathrm{BSA} / \mathrm{AFB}_{1} / \mathrm{GCE}$ immunosensor was successfully applied for $\mathrm{AFB}_{1}$ determination in rice samples with acceptable recovery range of 98.0-101.1\%, which demonstrated that the proposed method could be a suitable candidate for $\mathrm{AFB}_{1}$ detection in food industries.

Keywords: Aflatoxin $\mathrm{B}_{1}$; B, N dual-doped grapheme (BN-G); BS-G/Au@Pt NRs; Electrochemical immunosensor

\section{$\underline{\text { FULL TEXT }}$}

(C) 2020 The Authors. Published by ESG (www.electrochemsci.org). This article is an open access article distributed under the terms and conditions of the Creative Commons Attribution license (http://creativecommons.org/licenses/by/4.0/). 